\title{
THE IFIP INTERNATIONAL PROFESSIONAL PRACTICE PARTNERSHIP
}

\section{Transforming and Informing IT Professional Practice}

\author{
Charles Hughes, Chair \\ International Professional Practice Partnership
}

\begin{abstract}
A global programme led by IFIP (The International Federation for Information Processing) to promote professionalism in IT, define international standards and create a global infrastructure that will encourage and support the development of both practitioners and employer organisations and give recognition to those who meet and maintain the required standards for knowledge, experience, competence and integrity.
\end{abstract}

\section{The Vision}

Our vision is the creation of an international IT profession, equivalent in prestige and structure to other established professions such as law, accountancy and medicine, that is:

- Focused on improving the ability of business and other organisations to exploit the potential of information technology effectively and consistently.

- Respected by its stakeholders - including employees, employers, customers, governments and key international bodies.

- A source of real pride and aspiration for IT practitioners.

\section{The Background}

The IT profession is at a critical point in its development. IT is now quite clearly an activity which is vital to the world economy and to the prosperity and quality of life of ordinary people across the world. At the same time it is marked by an almost complete absence of well established national or international standards to assure the essential requirements of a truly professional practitioner. While a confusing array of examination-based qualifications provide an indication of relevant knowledge, it is generally impossible to validate subjective judgements about the experience, competence or ethical standards of individuals - even where those judgements relate to 
business-critical or even safety-critical positions. In a global industry in which practitioners are numbered in millions, this is very clearly unacceptable.

This lack of established national and international standards is a serious problem in a world in which everyone is now acutely aware of the need for IT professionalism - but it also provides a valuable opportunity. The IT profession stands on a cusp - sufficiently mature to recognise the importance of professionalism but not so far down the track that every nation has developed its own standards that would now require difficult and time consuming retrofitting to form an international standard. It is this unique and possibly short lived, opportunity that IFIP is determined to seize and exploit.

\section{IP3 - Delivering the Vision}

The IFIP International Professional Practice Partnership (IP3) is designed to deliver the vision set out above by the development of an overarching professional framework maintained and delivered through its network of over 90 national member societies.

The approach is essentially inclusive, intended neither to reinvent the wheel nor to supplant existing certifications. Rather the aim is to embrace and incorporate existing capabilities, strengthening and augmenting existing certification schemes by giving them a broader professional context and coherence, setting them in an architecture and generally promoting the value of standards, certifications and accreditations. The overriding aim is to develop, and to give recognition to individual practitioners and to IT employers who are ethical, experienced and competent and can be relied upon to form sound judgments and to make rational and principled decisions - qualities and capabilities that are especially important in our fastmoving business and rapidly changing technological world.

The profession reflected in the vision is one that has an extensive range of skills, encompassing not only the essential technical and engineering skills but also the key business focussed skills that ensure real business benefit. A vital role will be played by newer IT skills such as information management and business change management and it is particularly important that recognition is given to the growing importance of IT professionals in areas such as corporate governance and enterprise security

An essential feature of these arrangements will be encouraging and supporting development. Whilst certifications provide valuable markers on the path to full professionalism, it is equally important to provide the resources to support the development of knowledge, skills, competence and best professional practice for both individual practitioners and their employer organisations at all stages of that journey. 


\subsection{The Key Features of IP3 Certification}

IP3 certification schemes, of which the first will be the 'gold standard' International IT Professional (IITP) certification, will be:

- Vendor independent;

- Operated by accredited IFIP member bodies;

- Available worldwide;

- Based on consistent global standards for professionals in all areas of IT activity;

- Built around a requirement for complete professional formation including relevant knowledge, experience, competence and commitment to a code of professional ethics;

- Dependent on the maintenance of competence through a programme of continuing professional education and development;

- Supported by a disciplinary code with a process.

\section{Why IFIP?}

IFIP, with its UNESCO provenance, established reputation and existing infrastructure of over 90 independent, national member bodies and combined membership of around 1 million IT practitioners is uniquely qualified to lead this programme. There is no other organisation with the necessary independence, reputation and international reach that could contemplate the development, far less the delivery, of the proposed professionalism metaframework.

IFIP leadership also brings the advantage of significant and increasing national and international influence, both though IFIP itself and through its major member bodies. It also enables us to build on the very solid foundations established by a number of those bodies, including the British Computer Society the Australian Computer Society, the Canadian Information Processing Society and the IEEE Computer Society.

One of the key objectives for IP3 is to reach beyond the developed world, to encourage and facilitate the development of IT capability within the emerging nations. Here too the IFIP international infrastructure provides unique advantage.

\section{Partners Organisations}

Although IFIP is clearly the appropriate body to lead the development, delivery and management of the proposed professionalism framework, it needs the commitment, support and involvement of the industry. As the programme moves forward there will be opportunities for organisations of all kinds, both large and small, to associate themselves with the work. At this early stage we want to partner with a small group (probably no more 
than 4) of global organisations that share both our professionalism commitment and aspirations. For these Platinum Sponsors this involvement will provide opportunities to:

- Associate their brands with IT professionalism in a global context;

- Align their own IT professional development efforts with those of a global organization;

- Create and/or benchmark programs for the development of IT professionals;

- Participate in the development of standards for IT professionalism;

- Support and participate in building IT capability beyond the developed world.

\section{Summary}

We have a unique opportunity to put in place an urgently needed professional structure to underpin the competence and professionalism of IT practitioners and organisations on an international basis. IFIP, through the IP3 proposals outlined above, is committed to lead the development of that structure and invites support for a ground-breaking programme which will be of immense value to both the IT industry and to its stakeholders. 